\title{
Canadian restaurant industry opposes calorie content disclosure
}

Published at www.cmaj.ca on Oct. 27

$\mathrm{P}$ osting calorie information on menus would be "punitive" to the restaurant industry and isn't warranted because there is not enough evidence that proves doing so would result in substantial health gains, the Canadian Restaurant and Foodservice Association told delegates to an international conference on public health nutrition on Oct. 25.

But the association would be willing to work with public policy-makers to draft standards for sharing nutrition information with consumers and will support a national regulatory approach to enforcing those standards, Ron Reaman, the association's vice-president federal (government affairs) told the Championing Public Health Nutrition 2010 conference in Ottawa, Ontario.

"We recognize we have a role to play in improving the health of Canadians and we're not shying away from that responsibility. We're committed to being part of the solution but it has to make sense for both our customers and the industry and I believe those things are not, in fact, mutually exclusive."

Nevertheless, the responsibility of restaurant owners to Canadians does not include posting calorie information on menus, Reaman said. "I don't believe that running into a regulatory intervention that is potentially punitive to industry is the way to go," he noted, arguing that there is insufficient evidence that posting calorie information on menus results in substantial health gains.

Bill Jeffery, national coordinator of the Centre for Science in the Public Interest, which organized the conference, calls that stance a "public communications exercise."

"The restaurant industry is extremely good at providing food in an efficient and speedy way but they're notoriously clumsy and inconvenient in the way they provide objective information about

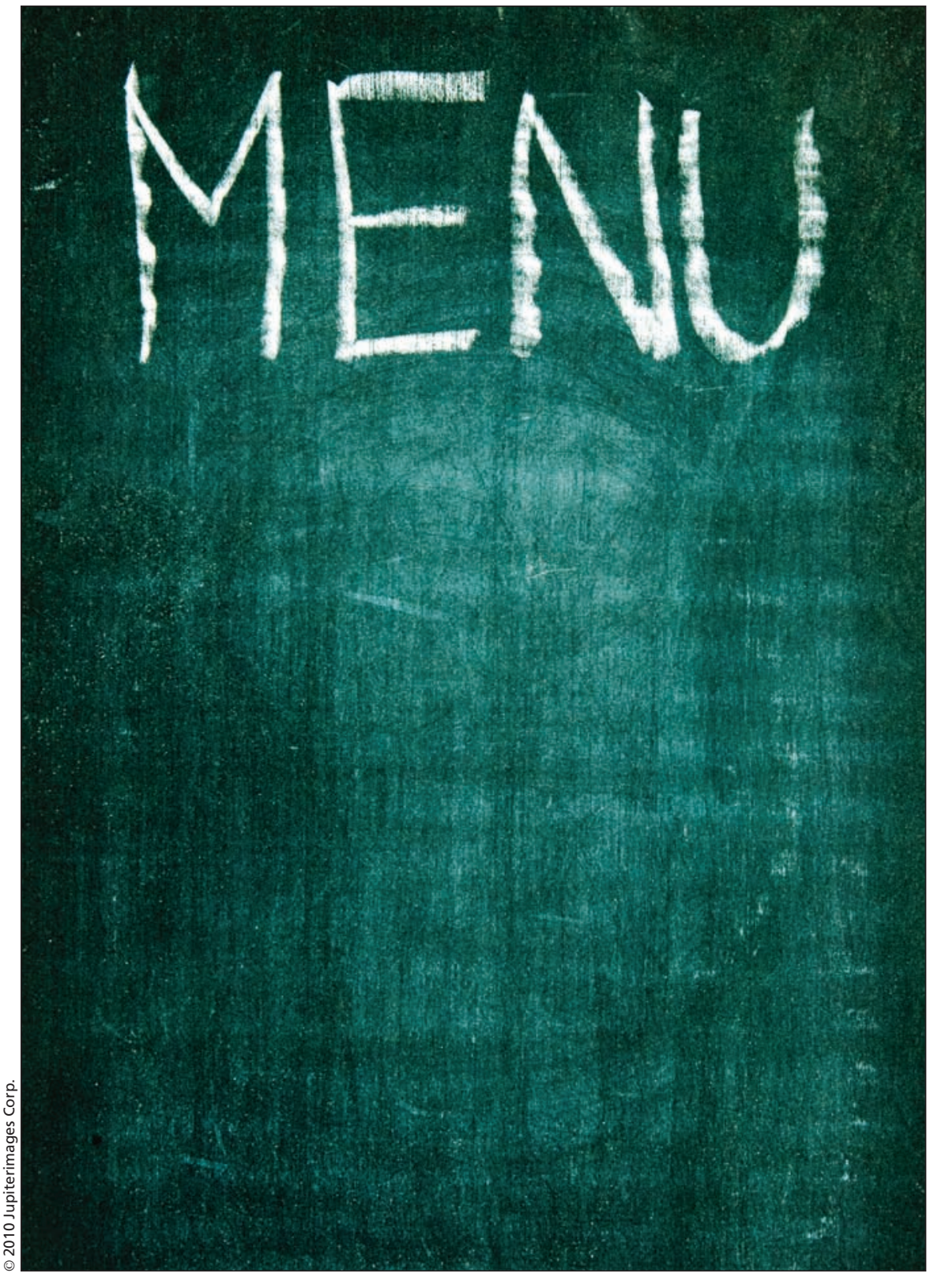

Menu boards should not include calorie content information, the Canadian Restaurant and Foodservice Association argues.

food," he says. "While a McDonald's tray liner might list 2000 nutrition numbers, it's all in font about a millimetre tall. Plainly they don't want to provide information in a way that's going to let people make an informed choice."
Reaman said some 33 national brands representing over $60 \%$ of the restaurant and foodservice industry (by revenue) participate in the association's voluntary nutrition information disclosure program. 
But only $0.1 \%$ of customers at four major fast food chains use the information provided by restaurants under the voluntary regime, said Dr. Yoni Freedhoff, medical director of Ottawa's Bariatric Medical Institute, who claimed studies show that "if you so much as looked at a menu board, or touched a pamphlet, whether you actually read them or not, you were counted as having accessed that information. Some 4300 people were monitored and only six people actually utilized the information."

Part of the problem is that the information provided by the restaurant industry is too complex, or too difficult, to access, says Jeffery. "I once asked for nutrition information from one of the participating restaurants and I was given a binder that was 200 pages long. Just looking for one menu item was an exercise in frustration."

Research supports the notion that nutrition information should be easy to understand and compare across food items, said Phillip Leslie, a professor of economics at Stanford University's Graduate School of Business in Palo Alto, California. "One thing we've learned from the literature over the last 20 or 30 years is that if these policies are going to have effect, the information must be simple."

Posting calorie information is a "no brainer," Freedhoff told delegates. "There may be more to nutrition than just calories, but if we had to pick one thing to be the price tag, calories are the currency of weight. When it comes to price tags, there's other info I might want to know if I was buying a shirt, for example, such as whether it was manufactured using child labour. But ultimately the most important thing I need to know is the price tag, and I can look elsewhere for that additional information."

New York City, New York, was the first jurisdiction to require restaurants to post calorie information, alongside prices, in 2008. That requirement went national in the United States this year as part of US President Barack Obama's health care reform package.

A similar bill introduced in the Ontario legislature earlier this year would mandate restaurants with over $\$ 5$ million in annual revenue to post calorie content directly on menus and menu boards. Sponsored by Ontario Member of Provincial Parliament France Gélinas in 2009, the bill narrowly passed second reading before the legislative session was prorogued.
"It was shocking to hear so many MPPs both from liberal and conservative parties repeat the propaganda that the restaurant and foodservice industry had fed them, saying the bill would bankrupt businesses, that there would need to be different information provided for every possible combination a consumer could think of and therefore it was not feasible," Gélinas told delegates. "Totally ignoring the fact that menu labelling has been functioning in American jurisdictions for years and ignoring the relative ease of implementation for large scale restaurants and the urgent obesity crisis we have on our hands."

Reaman declined comment on how industry standards would address concerns that have been raised about the existing voluntary disclosure program, or might improve on the proposed legislation in Ontario.

"It's early days still," he says. "As for the voluntary program, is it perfect? No. Is there room for improvement? Absolutely. I think what we need to do is test the kind of mechanism we already have in place and evolve our policy positions based on that evidence." Lauren Vogel, CMAJ

DOI:10.1503/cmaj.109-3716 